\title{
Synthesis and Spectral Studies of Copper (II) and Manganese (II) Complexes Using 2-Hydroxybenzyl-(pyridine-2-carbo)Iminohydrazone and 2-Furyl(pyridine-2-carbo)Iminohydrazone: Evaluation of Their Magnetic, and Antimicrobial Properties
}

\author{
Jagvir Singh, Anu, and NetraPal Singh \\ Department of Chemistry, Meerut College, (CCS University), Meerut 250001, India \\ Correspondence should be addressed to NetraPal Singh; netrapal_chem@yahoo.com
}

Received 11 June 2012; Accepted 22 July 2012

Academic Editor: D. Sajan

Copyright (C) 2013 Jagvir Singh et al. This is an open access article distributed under the Creative Commons Attribution License, which permits unrestricted use, distribution, and reproduction in any medium, provided the original work is properly cited.

Three new coordination complexes $\left[\mathrm{Cu}(\mathrm{HPBH})_{2}\right] \mathrm{Cl}_{2}(1),\left[\mathrm{Cu}(\mathrm{FPFH})_{2}\right] \mathrm{Cl}_{2}(2)$, and $\left[\mathrm{Mn}(\mathrm{HPBH})_{2}\right] \mathrm{Cl}_{2}$ (3) (where $\mathrm{HPBH}=2$ Hydroxybenzyl(pyridine-2-carbo)iminohydrazone, and FPFH=2-furyl(pyridine-2-carbo)iminohydrazone) have been synthesized using two different tridentate hydrazones ligand. The ligands were prepared by condensation of Pyridine-2-acetylchloride, 2Hydroxybenzaldehyde and Furan-2-carbaldehyde with hydrazine, respectively, in spite of varying the carbonyl functionality attached to the pyridine moiety present in the hydrazones ligand. In both the Schiff bases, we obtained three mononuclear complexes 1,2 , and 3 which were clearly characterized from physicochemical studies. Spectroscopic investigations like ${ }^{1} \mathrm{H}$ and ${ }^{13} \mathrm{C}$ NMR, mass spectrometric, FTIR, and UV/Vis have been carried out for new compounds. For complexes 2 cyclic voltammetry, magnetic and EPR properties have also been recorded. Antimicrobial studies have also been performed for these compounds with different antimicrobial species.

\section{Introduction}

Hydrazones are important class of ligands with interesting ligation properties due to the presence of several coordination sites [1] and are widely applied in the field of insecticides, medicines, and analytical reagents due to their excellent bioactivity [2]. Various important properties of carbonic acid hydrazides along with their applications in medicine and analytical chemistry have led to increased interest in their complexation characteristics with transition metal ions [3]. In this respect, the formation of metal complexes plays an important role to enhance their biological activity [4]. Studies have also shown that the azomethine nitrogen which has a lone pair of electrons in an $\mathrm{sp}^{2}$ hybridised orbital has considerable biological importance. Hydrazone derivatives are found to possess antimicrobial, antitubercular, anticonvulsant, and antiinflammatory activities [5-11]. The problem of resistance to antimicrobial activity is being addressed by medicinal chemists, and various strategies have been devised and attempted in order to enhance the activity or broaden the spectrum of drugs [12]. It has been demonstrated that transition elements play a very important role in various medicinal compounds. Coordination chemistry of manganese has been studied extensively $[13,14]$ due to its occurrence in the active site of several enzymes involved in the chemistry of reactive oxygen species [15]. EXAFS studies for the oxygen-evolving complex (OEC) [16] and crystal structure of the manganese peroxidase (isolated from Phanerochaete chrysosporium) [17] show that manganese center is surrounded by $\mathrm{O}-$ or $\mathrm{N}$ donor ligands. Manganese complexes having tetradentate ONNO donor ligands are found to be artificial mimics of some of these enzymes. In addition, they also act as catalysts for important reactions [18]. In this paper we synthesized copper(II) and manganese(II) complexes with 


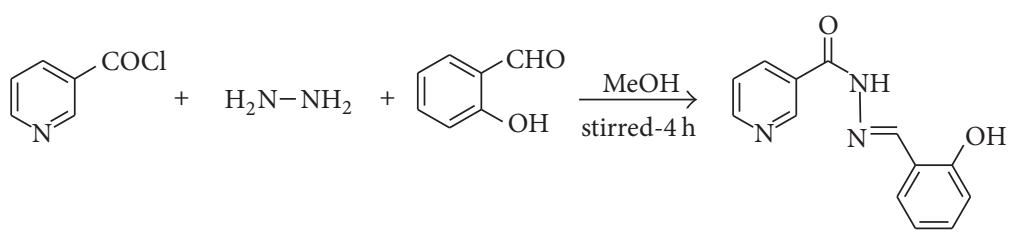

Scheme 1: Route for the synthesis of the 2-Hydroxybenzyl-(pyridine-2-carbo)-iminohydrazone.

TABLE 1: Synthesis of the 2-Hydroxybenzyl-(pyridine-2-carbo)-iminohydrazone and 2-furyl-(pyridine-2-carbo)-iminohydrazone Ligand.

S. no. Substrate (1) Substrate $(2+3)$

different pyridine hydrazones ligand. The structures of the ligand and metal complexes were characterized by elemental and thermal analyses, IR, Mass bar, EPR, ${ }^{1} \mathrm{H}$ and ${ }^{13} \mathrm{C} \mathrm{NMR}$, and electronic spectra as well as conductivity and magnetic susceptibility measurements at room temperature. The ligand and its metal complexes showed antibacterial activity against S. aureus ATCC 29253, S. aureus ATCC 3160, bacteria and antifungal activity towards the fungi Candida albicans (227) and Staphylococcus cerevisiae.

\section{Experimental}

All the chemicals used in the present investigation were of the analytical reagent grade (AR). Pyridine-2-acetylchloride, Furan-2-carbaldehyde, 2-Hydroxybenzaldehyde (Fisher Scientific), Hydrazine (Chemical Drug House, India), all metal salts and solvents (Qualigens Fine Chemicals, India) were purchased and used as received. The elemental analysis $(C, H$, $\mathrm{N}$ ) was done at the Regional Sophisticated Instrumentation Centre, Central Drug Research Institute, Lucknow. ${ }^{1} \mathrm{H}$ NMR and ${ }^{13} \mathrm{C}$ NMR spectra of the samples were measured in DMSO- $\mathrm{d}_{6}$ at IIT Delhi, India. The IR spectra were recorded as $\mathrm{KBr}$ pellets using a Perkin-Elmer 783 spectrophotometer in the range 4000-400. UV/vis spectra of the complexes were recorded on a Shimadzu UV-1601 spectrophotometer. The EPR spectra of the complexes were recorded as polycrystalline sample on a Varian E-4 EPR Spectrometer.

\subsection{Synthesis of Ligand}

2.1.1. Ligand 1. In a round bottom flask $(100 \mathrm{~mL})$, a methanolic solution $(10.0 \mathrm{~mL})$ of Pyridine-2-acetyl chloride
$(0.001 \mathrm{mmol}, 0.141 \mathrm{~mL})$ in an aqueous methanolic solution $(10 \mathrm{~mL})$ of hydrazine $(0.001 \mathrm{mmol}, 0.154 \mathrm{~g})$ and 2 Hydroxybenzaldehyde $(0.001 \mathrm{mmol}, 0.102 \mathrm{~mL})$ in methanol $(5 \mathrm{~mL})$ were taken and continued stir to at room temperature $\sim 4 \mathrm{~h}$. A yellowish crystalline solid was obtained as shown as Scheme 1. After the completion of this reaction, the product was monitored by thin layer chromatography and was taken in methanol and washed with hot water $(3 \times 20 \mathrm{~mL})$ and then with brine solution $(3 \times 20 \mathrm{~mL})$, and then the solvent under reduced pressure to afford the product (Table 1).

2.1.2. Ligand 2. In a round bottom flask $(100 \mathrm{~mL})$, $0.001 \mathrm{mmol}$ Pyridine-2-acetyl chloride $(0.141 \mathrm{~mL})$, in an aqueous methanolic solution $(10 \mathrm{~mL})$ of hydrazine (1.7 mmol, $0.154 \mathrm{~g}$ ) and $0.001 \mathrm{mmol} \mathrm{2-Furanecarboxalde-}$ hyde $(0.960 \mathrm{~g})$ in water $(5 \mathrm{~mL})$ were taken and continued to stir at room temperature $1 / 2 \mathrm{~h}$ and then reflux the reaction mixture about $2 \mathrm{~h}$. After the completion of this reaction, the reaction mixture was monitored by thin layer chromatography. Then, the reaction mixture was taken in methanol and washed with hot water $(3 \times 20 \mathrm{~mL})$ (thrice) and then with brine solution $(3 \times 20 \mathrm{~mL})$ (thrice), and then the solvent under reduced pressure was evaporated to afford the product; orange crystalline powder was obtained (Scheme 2) (Table 1).

2.1.3. Analytical Data of the Ligand HPBH and FPFH. Ligand $\left(\mathrm{C}_{13} \mathrm{H}_{10} \mathrm{~N}_{3} \mathrm{O}_{2}\right)$ :Yield: 52\%; M.P. $230^{\circ} \mathrm{C}$, Mol. wt. 241, color: yellowish; analytical data for $\mathrm{HPBH}$ found (calc.): $\mathrm{C}, 63.73$ (63.11); H, 4.56 (4.21); N, 17.42 (16.97). IR (KBr, cm $\left.{ }^{-1}\right)$ : 


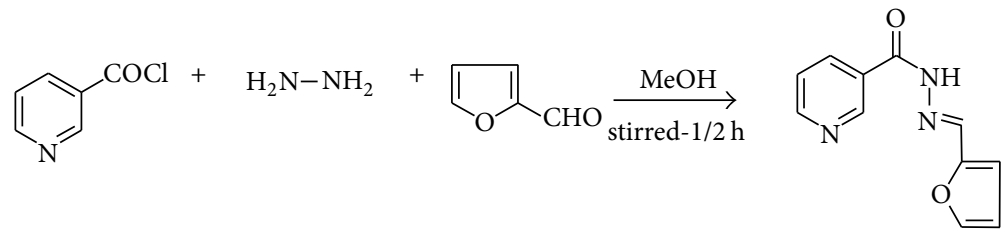

Scheme 2: Route for the synthesis of the 2-furyl-(pyridine-2-carbo)-iminohydrazone Ligand.

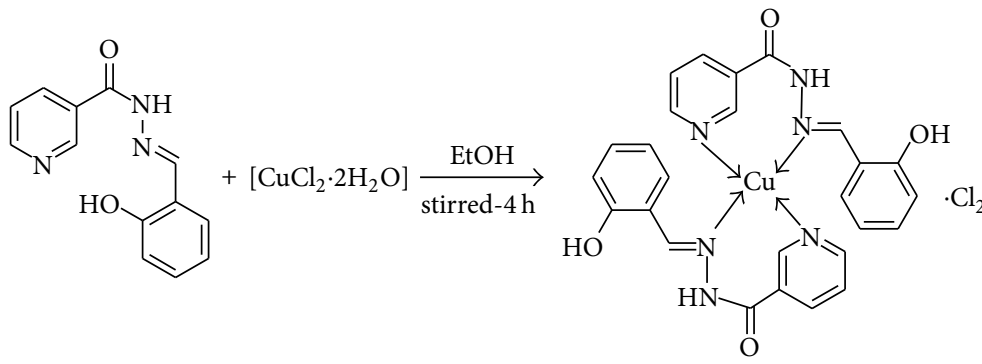

SCHEme 3: Route for the synthesis of the copper complex.

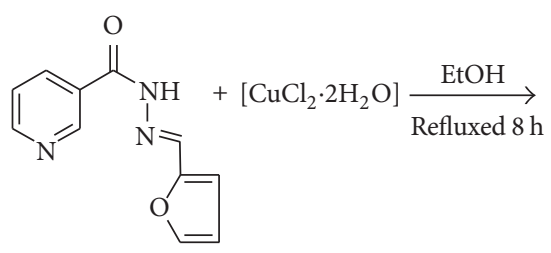<smiles></smiles>

Scheme 4: Route for the synthesis of the copper complex.

$3216 v_{\mathrm{NH}}, 1690 v_{\mathrm{C}=\mathrm{O}}, 1640 v_{\mathrm{C}=\mathrm{N}}, 3415 v_{\mathrm{OH}}, 2228 v_{\mathrm{C}-\mathrm{N}}$. ESIMS, m/z Data found (calc.): 241 (240), ${ }^{1} \mathrm{H}$ NMR (DMSO$\left.\mathrm{d}_{6}\right) \delta \mathrm{ppm}: 1.601(\mathrm{~s}, 1 \mathrm{H}, \mathrm{OH}-\mathrm{Ar}), 7.158-7.953(\mathrm{~m}, 8 \mathrm{H}$, Ar), $8.92(\mathrm{~s}, 1 \mathrm{H}, \mathrm{CH}=\mathrm{N}) .{ }^{13} \mathrm{C} \mathrm{NMR}\left(\mathrm{DMSO}-\mathrm{d}_{6}\right) \delta \mathrm{ppm}$ : 117.53-121.07 (11C, CH-Ar.), 153.88 (1C, C=O), 164.95 (1C, $\mathrm{CH}=\mathrm{N})$.

Ligand $\left(\mathrm{C}_{11} \mathrm{H}_{10} \mathrm{~N}_{3} \mathrm{O}_{4}\right)$ : Yield: $60 \%$; M.P. $255^{\circ} \mathrm{C}$, Mol. wt. 216, color: Orange; analytical data for FPFH found (calc.): C, 61.11 (60.185); H, 4.62 (4.21); N, 19.44 (18.88). IR (KBr, $\left.\mathrm{cm}^{-1}\right): 3440 v_{\mathrm{NH}}, 1700 v_{\mathrm{C}=\mathrm{O}}, 1640 v_{\mathrm{C}=\mathrm{N}}, 1015 v_{\mathrm{C}-\mathrm{O}}, 2228$ $v_{\mathrm{C}-\mathrm{N}}$. ESI-MS, $m / z$ Data found (calc.): 216 (215), ${ }^{1} \mathrm{H}$ NMR (DMSO-d $\left.{ }_{6}\right) \delta$ ppm: 7.158-7.953 (m, 8H, Ar), 8.92 (s, 1H, $\mathrm{CH}=\mathrm{N}) .{ }^{13} \mathrm{C}$ NMR (DMSO-d 6 ) $\delta$ ppm: 117.53-121.07 (9C, $\mathrm{CH}-A r.), 153.88$ (1C, C=O), $164.95(1 \mathrm{C}, \mathrm{CH}=\mathrm{N})$.

\subsection{Synthesis of Metal Complexes}

2.2.1. Complex 1. A quantity of $(0.002 \mathrm{mmol}, 0.282 \mathrm{~g})$ of 2 Hydroxybenzyl (pyridine-2-carbo) iminohydrazone ligand was dissolved in $100 \mathrm{~mL}$ methanol, and a solution of copper chloride $(0.001 \mathrm{mmol}, 0.170 \mathrm{~g})$ in $25 \mathrm{~mL}$ methanol was added dropwise with continuous stirring; dark bluish product appeared after one night standing. The mixture was stirred for $4 \mathrm{~h}$ at $35^{\circ} \mathrm{C}$. The resulting precipitates were filtered and washed with acetone and dried over anhydrous calcium chloride in a vacuum desiccator (Scheme 3).

2.2.2. Complex 2. A hot $\sim 70$ aqueous ethanolic solution $(20 \mathrm{~mL}, 1: 1 \mathrm{v} / \mathrm{v})$ of the copper chloride metal salt $(0.001 \mathrm{mmol}, 0.170 \mathrm{~g})$ and a hot ethanolic solution $(20 \mathrm{~mL})$ of the 2-furyl (pyridine-2-carbo) iminohydrazone $(0.001 \mathrm{mmol}$, $0.216 \mathrm{~g}$ ) were mixed in the molar ratio $(1: 2)$. The mixture was refluxed for about $8 \mathrm{~h}$ at a temperature of $\sim 78^{\circ} \mathrm{C}$. On cooling the contents to a temperature $\sim 5^{\circ} \mathrm{C}$ the compounds were separated. After this the compound was taken in hot methanol and washed with hot water, and then the solvent under reduced pressure was evaporated to afford the product; bluish solid was obtained (Scheme 4).

2.2.3. Complex 3. An ethanolic solution of 2-Hydroxybenzyl (pyridine-2-carbo) iminohydrazone ligand (0.282 g, $0.002 \mathrm{~m}$ $\mathrm{mol}$ ) was added dropwise to a $0.001 \mathrm{~m}$ mol solution of manganese chloride $(0.197 \mathrm{~g})]$ in methanol solution with continuous refluxed at $55^{\circ} \mathrm{C}$ for $12 \mathrm{~h}$. One night standing, the 


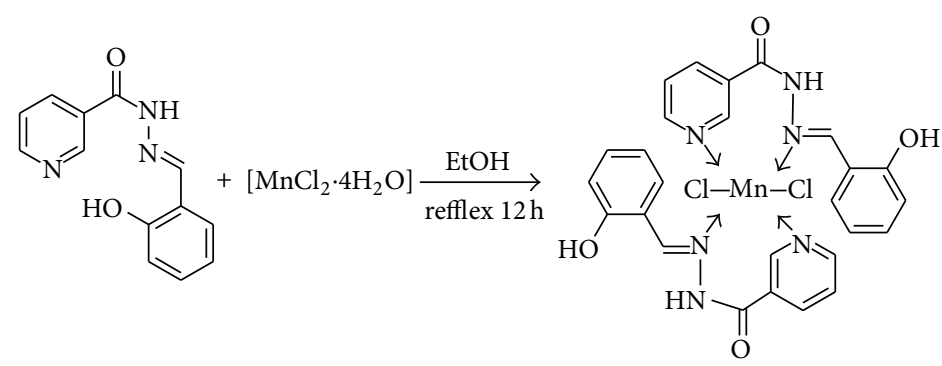

SCHEme 5: Route for the synthesis of the manganese complex.

reaction mixture was monitored by thin layer chromatography. The organic layers were collected; then crude products were taken in hot methanol and washed with water was evaporated and then the solvent under reduced pressure to afford the product; a dirty brownish solid was obtained (Scheme 5).

\subsection{Analytical Data of the Metal Complexes 1, 2 and 3}

2.3.1. Complex 1. Yield: $26 \%$; MP: $256^{\circ} \mathrm{C}$; Mol. wt. 722 ; color: bluish; analytical data for $\left[\mathrm{CuC}_{26} \mathrm{H}_{20} \mathrm{~N}_{6} \mathrm{O}_{4}\right] \mathrm{Cl}_{2}$ found (calc.): C, 43.21 (42.15); H, 2.77 (2.11); N, 11.63 (11.17); IR (KBr, $\left.\mathrm{cm}^{-1}\right): 3216 v_{\mathrm{NH}}, 1700 v_{\mathrm{C}=\mathrm{O}}, 1602 v_{\mathrm{C}=\mathrm{N}}, 3415 v_{\mathrm{OH}},{ }^{1} \mathrm{H}$ NMR (DMSO-d $\left.{ }_{6}\right) \delta$ ppm: 1.601 (s, 1H, OH-Ar), 7.158-7.953 (m, $8 \mathrm{H}, \mathrm{Ar}), 8.92(\mathrm{~s}, 1 \mathrm{H}, \mathrm{CH}=\mathrm{N}) .{ }^{13} \mathrm{C} \mathrm{NMR}\left(\mathrm{DMSO}-\mathrm{d}_{6}\right) \delta \mathrm{ppm}$ : 117.53-121.07 (11C, CH-Ar.), 153.65 (1C, C=O), 164.85 (1C, $\mathrm{CH}=\mathrm{N})$.

2.3.2. Complex 2. Yield: $25 \%$; MP: $268^{\circ} \mathrm{C}$; Mol. wt. 672 ; color: bluish; analytical data for $\left[\mathrm{CoC}_{22} \mathrm{H}_{20} \mathrm{~N}_{6} \mathrm{O}_{4}\right] \mathrm{Cl}_{2}$ found (calc.): C, 36.40 (35.15); H, 2.52 (2.11); N, 14.15 (13.17); IR (KBr, $\left.\mathrm{cm}^{-1}\right): 3440 v_{\mathrm{NH}}, 1700 v_{\mathrm{C}=\mathrm{O}}, 1608 v_{\mathrm{C}=\mathrm{N}}, 1015 v_{\mathrm{C}-\mathrm{O}} ;{ }^{1} \mathrm{H}$ NMR (DMSO-d $\left.{ }_{6}\right) \delta$ ppm: 7.158-7.953 (m, 8H, Ar), $8.92(\mathrm{~s}, 1 \mathrm{H}$, $\mathrm{CH}=\mathrm{N}$ ). ${ }^{13} \mathrm{C}$ NMR (DMSO-d 6 ) $\delta$ ppm: 117.53-121.07 (9C, CH-Ar.), 153.88 (1C, C=O), $164.95(1 \mathrm{C}, \mathrm{CH}=\mathrm{N})$.

2.3.3. Complex 3. Yield: $47 \%$; MP: $276^{\circ} \mathrm{C}$; Mol. wt. 749; color: dirty brownish; analytical data for $\left[\mathrm{MnC}_{26} \mathrm{H}_{20} \mathrm{~N}_{6} \mathrm{O}_{4} \mathrm{Cl}_{2}\right]$ found (calc.): C, 41.65 (40.68); $\mathrm{H}, 2.67(2.11) ; \mathrm{N}, 11.21$ (11.17); IR $\left(\mathrm{KBr}, \mathrm{cm}^{-1}\right): 3216 v_{\mathrm{NH}}, 1700 v_{\mathrm{C}=\mathrm{O}}, 1602 v_{\mathrm{C}=\mathrm{N}}$, $3415 v_{\mathrm{OH}},{ }^{1} \mathrm{H}$ NMR (DMSO-d 6 ) $\delta$ ppm: 1.601 (s, 1H, OHAr), 7.158-7.953 (m, 8H, Ar), $8.92(\mathrm{~s}, 1 \mathrm{H}, \mathrm{CH}=\mathrm{N}) .{ }^{13} \mathrm{C} \mathrm{NMR}$ (DMSO-d 6 ) $\delta$ ppm: 117.53-121.07 (11C, CH-Ar.), 153.65 $(1 \mathrm{C}, \mathrm{C}=\mathrm{O}), 164.85(1 \mathrm{C}, \mathrm{CH}=\mathrm{N})$.

\section{Results and Discussion}

The IR spectra of 1,2 , and 3 were analyzed in comparison with that of their respective free ligand $(\mathrm{HPBH}$ and $\mathrm{FPFH})$ in the region 4,000-400 $\mathrm{cm}^{-1}$. The IR spectra of the hydrazones contain a strong C-O absorption band at 1,651-1,659 $\mathrm{cm}^{-1}$ and $\mathrm{N}-\mathrm{H}$ absorption band at $3,187-3,250 \mathrm{~cm}^{-1}$. Both of these bands disappear on complexation of two, and a new C-O absorption band appears at $1,040-1,089 \mathrm{~cm}^{-1}$ in this complex, indicating that the hydrazones ligands have undergone deprotonation on complexation. These data give evidence for the coordination of the ligand $(\mathrm{HPBH}$ and $\mathrm{FPFH})$ to the respective metal ions ( $\mathrm{Cu}$ (II) and $\mathrm{Mn}$ (II)) via two nitrogen atoms and oxygen atom. The infrared spectra of 1, 2, and 3 display IR absorption bands at $1,637 \mathrm{~cm}^{-1}$, $1,583 \mathrm{~cm}^{-1}$, and $1,587 \mathrm{~cm}^{-1}$ which can be assigned to the $\mathrm{C}=\mathrm{N}$ stretching frequencies of the coordinated ligands $(\mathrm{HPBH}$ and $\mathrm{FPFH})$, whereas for the free ligand $(\mathrm{HPBH}$ and $\mathrm{FPFH}$ ) the same bands are observed at $1,682 \mathrm{~cm}^{-1}$ and $1,685 \mathrm{~cm}^{-1}$, respectively. The shift of these bands on complexation towards lower wave number indicates coordination of the azomethane nitrogen to the metal centre. The ligand coordination to the metal centre is substantiated by two bands appearing at $412 \mathrm{~cm}^{-1}, 414 \mathrm{~cm}^{-1}, 416 \mathrm{~cm}^{-1}$ for 1,2 , and 3 , respectively, which are mainly attributed to $v(\mathrm{M}-\mathrm{N})$ [19] and at $380 \mathrm{~cm}^{-1}$ for 2 which are mainly attributed to $v$ (M-O) group [20]. The low energy pyridine ring in plane and out of plane vibrations was observed in the spectrum of the two ligands 625 and $635 \mathrm{~cm}^{-1}$, respectively, whereas the corresponding bands for the complexes were shifted to higher frequencies $631-608 \mathrm{~cm}^{-1}, 662-682 \mathrm{~cm}^{-1}$, and $690-714 \mathrm{~cm}^{-1}$ for 1,2 , and 3, respectively, which is a good indication of the coordination of the heterocyclic nitrogen. The EPR spectra of the Co (II) complexes were recorded as polycrystalline sample at LNT since the rapid spin lattice relaxation of $\mathrm{Cu}$ (II) broadens the lines at higher temperature. The $g$ values lie in the range $g_{\mathrm{II}} 2.912-2.914$ and $g_{\perp} 2.504-2.514$ [21]. The copper complex parameters are consistent with tetragonally elongated octahedral geometry $\left(g_{\mathrm{II}}>g_{\perp}>2.0\right)$, and the unpaired electron occupies predominantly the $d x^{2}-y^{2}$ orbital for the $\mathrm{Cu}$ (II) chelates. The value is consistent with the magnetically dilute high spin $\mathrm{d}_{5} \mathrm{Mn}$ (II) complex. EPR study of 3 The X-band EPR spectrum from a solution of $\left[\mathrm{Mn}(\mathrm{HPBH})_{2}\right](3)$ in DMSO at $10 \mathrm{~K}$ is shown in Scheme 5. The spectrum was recorded with the external magnetic field oriented either perpendicular or parallel to the microwave magnetic field. In perpendicular mode, signals are observed in a wide spectral region. A sextet of lines is observed at $g \sim 2.0$ which is attributed to Mn (II) $(S=5 / 2)$ system. In parallel mode, a broad signal is observed with a valley at $g \sim 5.45$. The spectrum is consistent with a $\mathrm{Mn}(\mathrm{II})(S=$ 5/2) monomer. The $\mathrm{X}$ band EPR signals show similarities with signals of other $\mathrm{Mn}$ (II) $(S=5 / 2)$ monomers. EI mass 
spectrum of the ligands showed molecular ion peak at $\mathrm{m} / \mathrm{z}$ 241 and $216 \mathrm{amu}\left(\mathrm{C}_{13} \mathrm{H}_{10} \mathrm{~N}_{3} \mathrm{O}_{2}\right.$ and $\mathrm{C}_{11} \mathrm{H}_{10} \mathrm{~N}_{3} \mathrm{O}_{4}$ calculated atomic mass 240 and $215 \mathrm{amu}$ ), and other peaks at 170 , $171,181,184$, and 188 may be due to different fragments. The weak peak described at $135 \mathrm{amu}$ is assigned to the fragment $\left[\mathrm{C}_{6} \mathrm{H}_{8} \mathrm{~N}_{4}\right]^{+}$, corresponding to the loss of $\mathrm{CO}$ group. A very weak peak at $119 \mathrm{amu}$ is assigned to the fragment $\left[\mathrm{C}_{6} \mathrm{H}_{6} \mathrm{~N}_{2}\right]^{+}$, corresponding to the loss of $\mathrm{CONH}_{2}$ group. The most intense peak at 91 corresponds to the fragment $\left[\mathrm{C}_{6} \mathrm{H}_{5} \mathrm{~N}\right]^{+}$. Other peaks at $88,78,60$, and 44 correspond to fragments $\left[\mathrm{CH}_{3} \mathrm{~N}_{3} \mathrm{O}\right]^{+},\left[\mathrm{C}_{5} \mathrm{H}_{4} \mathrm{~N}\right]^{+},\left[\mathrm{CONH}_{2}\right]^{+}$, and $[\mathrm{CO}]^{+}$, respectively. The intensity of theses peaks gives an idea of the stability of these fragments.

In the spectrums of UV-Vis spectroscopy with copper (II) salts in ethanol result in the formation of blue-colored compounds, the unsubstituted hydrazones complexes forming $\left[\mathrm{Cu}(\mathrm{HPBH} / \mathrm{FPFH})_{2}\right] \mathrm{X}_{2}$ type of compound. Because of their very little solubility in noncoordinating solvents, they could not be recrystallized following their preparation. However, these indicate that the compounds obtained were quite pure and needed no further purification. The complexes were fairly stable, and the compound dissolves in coordinating solvents such as pyridine forming. The insolubility of these compounds has further precluded the possibility of determining their geometry in solution. The assignment of gross stereochemical features to copper (II) complexes from spectral data is made exceedingly difficult because of broadness of the major absorption maxima in some cases, arising from as many as three closely spaced electronic transitions, JahnTeller distortion and spin-orbital coupling. The electronic spectra of the copper (II) complex display a broad band at $14920 \mathrm{~cm}^{-1}$ due to ${ }^{2} \mathrm{~B}_{1 g} \rightarrow{ }^{2} \mathrm{E}_{g}$ and two bands at 16390 and $27250 \mathrm{~cm}^{-1}$ assigned to $\mathrm{d}-\mathrm{d}$ transitions and a charge transfer band, respectively, of an octahedral environment [22]. The first absorption band, in octahedral site symmetry, is taken to be equal to $10 \mathrm{Dq}$. The spectra of this complex yield, by standard treatment, values for the ligand field parameter Dq, $\mathrm{B}^{\prime}$, and $\beta^{\prime}$, making use of these values; energies of $\nu_{2}$ and $v_{3}$ have been calculated and checked against observed value, since this is the justification of having cubic symmetry. The calculated values of $v_{2}$ and $v_{3}$ are in close agreement with the experimental values. In descending the symmetry from $\mathrm{O}_{h}$ to $\mathrm{D}_{4 h}$ all the excited states that are observed in octahedral site symmetry are split into two levels, and three-band spectrums become a six-band spectrum and should, therefore, contain enough information to analyze satisfactorily. In practice, all the six bands are rarely seen and at room temperature and are generally rather broad because, in addition to several other reasons, principally they contain a number of component vibrational transitions. Considering the low energy transition first, two absorptions were noticed although the difference between the two bands is not large; the lowest energy transition is assigned to ${ }^{3} \mathrm{E}_{g}$ transition and the next higher energy band to the ${ }^{3} \mathrm{E}_{g}$ transition. The transition to the ${ }^{3} \mathrm{~B}_{2 g}$ state is dependent only on the in-plane ligand field strength, $10 \mathrm{Dq}$, for pyridine hydrazones moiety. Mn (II) complexes show three bands 20,491-20,366, 18,903-18,976 and $14,064-13,869 \mathrm{~cm}^{-1}$ assignable to ${ }^{4} \mathrm{~A}_{1 g}(4 \mathrm{G}) \rightarrow{ }^{6} \mathrm{~A}_{1 g}$, ${ }^{4} \mathrm{~T}_{2 g} \rightarrow{ }^{6} \mathrm{~A}_{1 g}(4 \mathrm{G})$ and ${ }^{4} \mathrm{~T}_{1} \mathrm{~g} \rightarrow{ }^{6} \mathrm{~A}_{1 g}(\mathrm{G})$ transitions, which lie in the same range as reported for octahedrally coordinated $\mathrm{Mn}$ (II) ion [23]. The magnetic moment 4.88 is an additional evidence for an octahedral structure. On the basis of the previous observations, it is tentatively suggested that all of the complexes show an octahedral geometries in which the ligands act as tridentates. These possibly accommodate themselves around the metal atoms in such a way that a stable chelate ring is formed giving, in turn, stability to the formed metal complexes.

\section{Cyclic Voltammogram}

From the cyclic voltametry analysis, we determine the maximum current and potential in which charge transfer complexes were stable and beyond that the charge transfer complexes get decomposed. Cyclic voltametry is a dynamic electrochemical method, where variation in current is recorded at well-defined applied potential depending on the scan rate; the current-potential curves are drawn. The measured oxidation potential of an electroactive substance correlates directly with the ionization potential $I_{p}$ and the reduction potential with the electron affinity $E_{a}$. Since the vacuum level potentials of the common reference electrodes can be estimated, the band edge positions of electroactive materials can be approximated. Ideally, one peak couple of oxidation and reduction potential should appear in the cyclic voltammogram measurement for the valence band (VB) and the conduction band (CB), respectively. Complex is first oxidized at the surface of the layer, and then the oxidized valence bands are filled up by electrons in the inner nonoxidized region of the layer, and reduction takes place. Voltammogram of these complexes displays a reduction peak at $E_{\mathrm{pc}}=-1.4 \mathrm{~V}$ with an associated oxidation peak at $E_{\mathrm{pa}}=-0.6 \mathrm{~V}$ at a scan rate of $50 \mathrm{mV} / \mathrm{s}$. The peak separation of this couple $\left(\Delta E_{p}\right)$ is $0.8 \mathrm{~V}$ and increases with scan rate. The $\Delta E_{p}$ is 1.1 and 1.4 at scan rates $100 \mathrm{mV} / \mathrm{s}$ and $200 \mathrm{mV} / \mathrm{s}$, respectively. Thus, the analyses of cyclic voltammetric responses at different scan rate give the evidence for quasireversible one electron reduction. The most significant feature of the copper(II) complex is the $\mathrm{Cu}$ (II)/Cu (I) couple. The ratio of cathodic to anodic peak height was less than one. However, the peak current increases with the increase of the square root of the scan rates. This establishes the electrode process as diffusion controlled.

\section{Thermogravimetric Analysis (TG/DTA)}

The thermal analysis (TG/DTA) of the ligand and its metal complexes was recorded under nitrogen atmosphere at the heating rate of $10^{\circ} \mathrm{C} / \mathrm{min}$. The ligand is stable up to $215^{\circ} \mathrm{C}$ and shows a continuous weight loss up to $380^{\circ} \mathrm{C}$. Therefore the whole ligand gets decomposed in a single step (Figure 1(a)). The DTA of the ligand shows two endothermic peaks, one broad endothermic peak at $228^{\circ} \mathrm{C}$ with a shoulder at $210^{\circ} \mathrm{C}$, which corresponds to the melting and the first inflexion point. The second inflexion on the DTA curve occurs at $351^{\circ} \mathrm{C}$ which represents a small weight loss step from $360^{\circ} \mathrm{C}$ to 


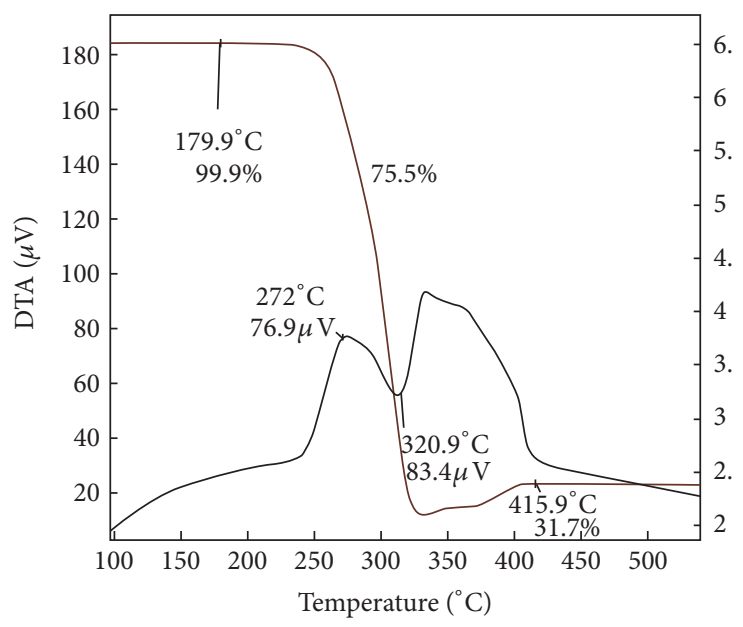

(a)

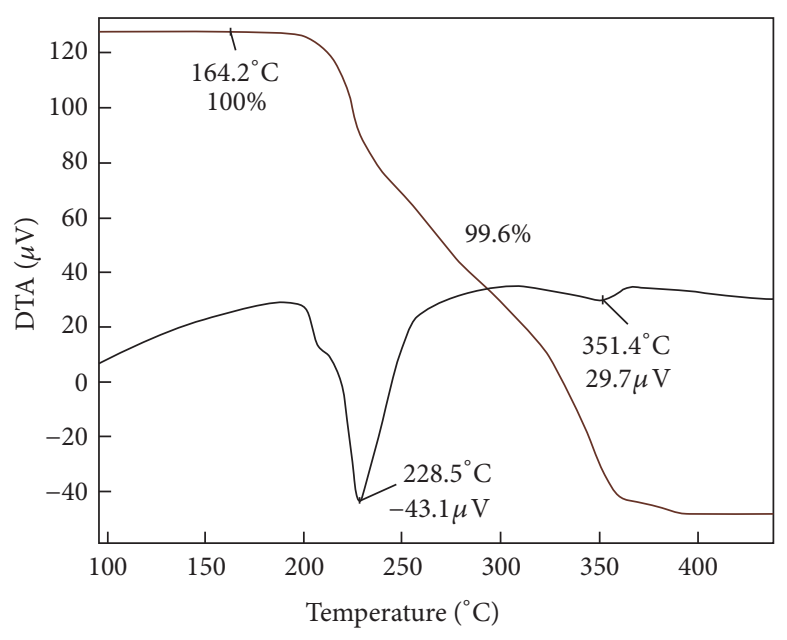

(b)

FIGURE 1: Thermal analysis of HPBH ligand (a) and their $\mathrm{Cu}(\mathrm{II})$ metal complex (b).

$380^{\circ} \mathrm{C}$. The thermal gravimetric (TG) analysis was used as a probe to prove the associated water or solvent molecules to be in coordination sphere or in crystalline form [24].

The thermogram of copper(II) and manganese (II) complexes is more stable than the hydrazones ligand and does not decompose up to $255^{\circ} \mathrm{C}, 253^{\circ} \mathrm{C}$, and $250^{\circ} \mathrm{C}$, respectively (Figure 1(b)). It shows a major step of decomposition from $255^{\circ} \mathrm{C}$ to $330^{\circ} \mathrm{C}$ which is detected by DTA at $320^{\circ} \mathrm{C}$; this corresponds to the loss of two pyridine ring and two imines moieties (observed weight 75.5\%, theoretical weight $72.85 \%$ ). It is very interesting to note that the complexes gain some $7 \%$ weight from $335^{\circ} \mathrm{C}$ to $410^{\circ} \mathrm{C}$ and do not decompose further. This weight gain of complexes may be attributed to the migration of the metal (Mlayer) to the new vacant sites produced by the partial reduction of $\mathrm{M}^{2+}$ to $\mathrm{M}^{1+}$ in case of Copper and $\mathrm{M}^{4+}$ to $\mathrm{M}^{2+}$ in case of cobalt and nickel, then subsequent oxidation of $\mathrm{M}^{1+}, \mathrm{M}^{2+}$ in copper, cobalt, and nickel complexes, respectively [25].

\section{Microbiology Properties}

In vitro antibacterial activity studies were carried out by using the standardized disc-agar diffusion method $[23,25,26]$ to investigate the inhibitory effect of the synthesized ligands and complexes against $S$. aureus ATCC 29253, S. aureus ATCC 3160 antibacterial, and S. cerevisiae MTCC 316, Candida albicans (227) as a kind of fungi. For the antibacterial and antifungal assays, the compounds were dissolved in dimethylformamide. Further dilutions of the compounds and standard drugs in the test medium were prepared at the required quantities of 500 and 1000 ppm concentrations with dextrose broth. The minimum inhibitory concentrations (MICs) were determined using the twofold serial dilution technique. A control test was also performed containing inoculated broth supplemented at the same dilutions used in our experiments and found inactive in the culture medium. Gentamycin and Amphotericin B were used as control drugs.
The data on the antimicrobial activity of the compounds and the control drugs as MIC values are given in Table 2. The cultures were obtained from SRL broth for all the bacterial strains after $24 \mathrm{~h}$ of incubation at $37^{\circ} \mathrm{C}$. C. albicans were maintained in dextrose broth after incubation for $24 \mathrm{~h}$ at $25^{\circ} \mathrm{C}$. Testing was carried out in dextrose broth at $\mathrm{pH} 7.4$ and the two fold serial dilution technique was applied. A set of tubes containing only inoculated broth was used as controls. For the antibacterial assay after incubation for $24 \mathrm{~h}$ at $37^{\circ} \mathrm{C}$ and after incubation for $48 \mathrm{~h}$ at $25^{\circ} \mathrm{C}$ for the antifungal assay, the last tube with no growth of microorganism and/or yeast was recorded to represent the MIC expressed in ppm. Every experiment in the antibacterial and antifungal assays was replicated twice, and the data is given in Table 2 .

The observation on the biological assay indicates that the antibacterial action due to all compounds has $\mathrm{N}, \mathrm{O}$ groups which is of considerable chemotherapeutic interest. From Figure 2 and Table 2, it is evident that among all the newly synthesized compounds 1, 2, and 3 tested for their antibacterial and antifungal activities against Staphylococcus aureus (ATCC 25923), Staphylococcus aureus (ATCC 3160), Cabdida albicans (227), and Staphylococcus cereviscae (361) were determined as MIC values. All the investigated compounds showed good activity against $S$. aureus. The zone of inhibition in $\mathrm{mL}$ of the test compounds against the microorganism Staphylococcus aureus (ATCC 25923), Staphylococcus aureus (ATCC 3160), Cabdida albicans (227), and Staphylococcus cereviscae (361). These data indicate that among the bacteria employed, $S$. aureus is found to be more sensitive to these compounds whereas the gram-negative bacteria show resistance to most of the compounds. The zone of inhibition tabulated reveals that the antibacterial activity of the compounds is specific to the microorganism examined. Analysis of the data showed that generally the fungi $C$. albicans (227) was more susceptible to the irreversible toxic effects of screened compounds than S. cereviscae (361). Variation in the response of fungi studies to chemical screened may be attributed to the tolerance of them by test fungi. The effects 
TABLE 2: Antimicrobial activity of hydrazones ligand and their metal complexes.

\begin{tabular}{|c|c|c|c|c|c|c|c|c|c|}
\hline \multirow{3}{*}{ Compounds } & \multirow{3}{*}{ Time hrs } & \multicolumn{8}{|c|}{ Diameter of zone of inhibition $(\mathrm{mm})$} \\
\hline & & \multicolumn{2}{|c|}{ S. aureus MTCC 3160} & \multicolumn{2}{|c|}{ S. aureus MTCC 25923} & \multicolumn{2}{|c|}{ C. albican MTCC 227} & \multicolumn{2}{|c|}{ S. cereviscae MTCC 361} \\
\hline & & $100 \mu \mathrm{g}$ & $50 \mu \mathrm{g}$ & $100 \mu \mathrm{g}$ & $50 \mu \mathrm{g}$ & $100 \mu \mathrm{g}$ & $50 \mu \mathrm{g}$ & $100 \mu \mathrm{g}$ & $50 \mu \mathrm{g}$ \\
\hline \multirow{2}{*}{$\mathrm{HPBH}$} & 24 & 40 & 41 & 41 & 42 & 23 & 12 & 13 & 15 \\
\hline & 48 & 42 & 45 & 43 & 43 & 25 & 15 & 15 & 18 \\
\hline \multirow{2}{*}{ FPFH } & 24 & - & - & 32 & 33 & 23 & 11 & - & - \\
\hline & 48 & - & - & 34 & 35 & 20 & 21 & - & - \\
\hline \multirow{2}{*}{1} & 24 & 10 & 12 & 13 & 16 & 19 & 17 & 19 & 18 \\
\hline & 48 & 11 & 14 & 14 & 19 & 11 & 10 & 12 & 19 \\
\hline \multirow{2}{*}{2} & 24 & 19 & 18 & 20 & 28 & 25 & 27 & 21 & 18 \\
\hline & 48 & - & - & - & - & 11 & 29 & 12 & 19 \\
\hline \multirow{2}{*}{3} & 24 & - & - & - & - & 13 & 10 & 12 & 10 \\
\hline & 48 & 14 & 10 & 13 & 12 & 14 & 13 & 14 & 11 \\
\hline \multirow{2}{*}{ Gentamycin } & 24 & 32 & 34 & 32 & 34 & - & - & - & - \\
\hline & 48 & 32 & 34 & 32 & 34 & - & - & - & - \\
\hline \multirow{2}{*}{ Amphotericin-B } & 24 & - & - & - & - & 17 & 21 & 17 & 21 \\
\hline & 48 & - & - & - & - & 17 & 21 & 17 & 21 \\
\hline
\end{tabular}

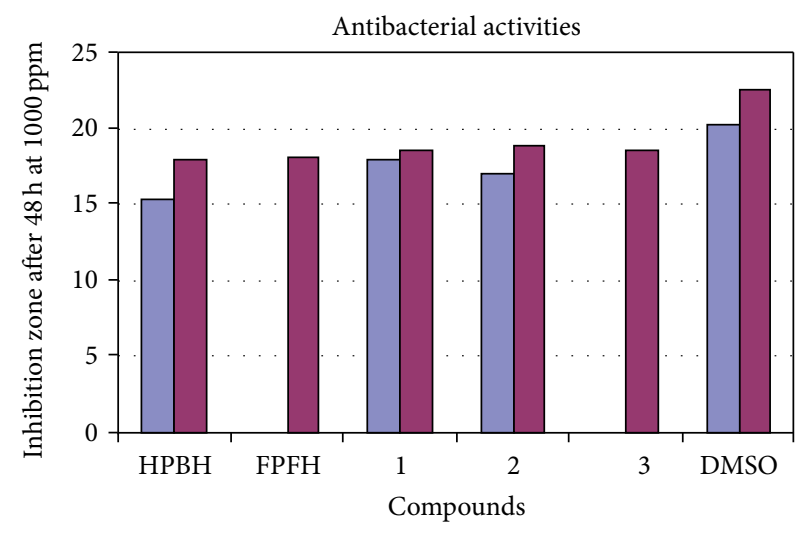

․ aureus 3160

- S. aureus 29253

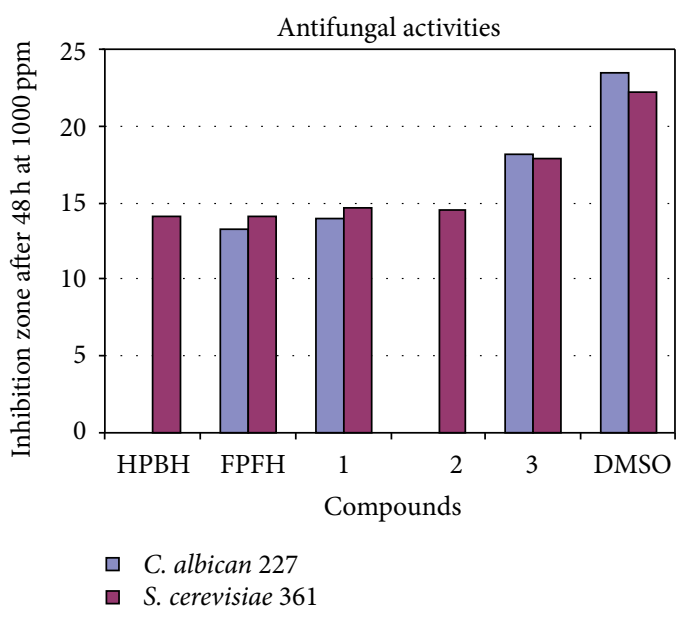

(b)

FIGURE 2: Showing the bar graph (a) and (b) of antibacterial and antifungal activities at 1000 ppm concentration after 48.

of assayed chemicals on test fungi differed in accordance with the concentrations used. Generally fungi toxicity enhanced with the increase in the dose of compounds. The higher the concentration, the longer was the persistence of chemicals.

\section{Conclusion}

This research work has achieved the synthesis of hydrazone tetradentate nitrogen and oxygen donor ligands. Using these ligands we synthesize the two $\mathrm{Cu}$ (II) and one $\mathrm{Mn}$ (II) metal complexes and screened them for their antimicrobial property by performing minimum inhibitory concentration (MIC). Antimicrobial results showed that metal complexes have high killing activity compared to the ligand. MIC values decreased almost stoichiometrically with multiplication of structure. A whole line of current antifungals target ergosterol biosynthesis pathway or its end product which is unique to fungi. At respective MIC values $\mathrm{Cu}(\mathrm{II})$ complexes lead to enormous reduction in ergosterol content followed by $\mathrm{Cu}$ (II) complex, $\mathrm{Mn}$ (II) complex, and the ligand, respectively.

\section{Acknowledgments}

The authors are thankful to SAIF, CDRI, Lucknow, SARC, Meerut, and ACBR, New Delhi, India, for providing the spectral, analytical facilities and biological activity, respectively.

\section{References}

[1] O. Hill and R. J. Magee, "The Thermochemistry of Metal Dithiocarbamate complexes and related compounds," Reviews in Inorganic Chemistry, vol. 3, pp. 141-197, 1981. 
[2] A. M. Bond and R. L. Martin, "Electrochemistry and redox behaviour of transition metal dithiocarbamates," Coordination Chemistry Reviews, vol. 54, pp. 23-98, 1984.

[3] J. O. Hill and S. Chirawongaram, "Thermal analysis studies of tin dithiocarbamate complexes-a short review," Journal of Thermal Analysis, vol. 41, no. 2-3, pp. 511-518, 1994.

[4] M. F. Rabbi, A. Finnegan, L. Al-Hartli, S. Stong, and K. A. Roebuck, "Interleukin-10 enhances tumor necrosis factor-alpha activation of HIV-1 transcription in latently infected T cells," Journal of Acquired Immune Deficiency Syndromes \& Human Retrovirology, vol. 19, no. 4, pp. 321-333, 1998.

[5] R. M. Topping and M. M. Jones, "Optimal dithiocarbamate structure for immunomodulator action," Medical Hypotheses, vol. 27, no. 1, pp. 55-57, 1989.

[6] A. Weuffen and A. Kewitsch, "Connection between chemical constitution and antimicrobial activity. 18. Orientating studies of the tuberculostatic properties of some dithiocarbamic acid esters (dithiourethanes) and dithiocarbamic salts," Archiv für Experimentelle Veterinärmedizin, vol. 21, no. 4, pp. 1049-1059, 1967.

[7] J. Bravo, M. B. Cordero, J. S. Casas, M. V. Castano, A. Sanchez, and J. Sordo, "Tautomerism in coordinated 1-phenyl5-thione-1,2,3,4-tetrazole (HL) Synthesis and crystal structure of $\left[\mathrm{SnMe}_{2}\right.$ (phen) $\left.\mathrm{L}_{2}\right]$ (phen = 1,10-phenanthroline)," Journal of Organometallic Chemistry, vol. 513, no. 1-2, pp. 63-67, 1996.

[8] B. El Ali, K. Okuro, G. Vasapollo, and H. Alper, "Regioselective palladium(II)-catalyzed synthesis of five- or seven-membered ring lactones and five-, six- or seven-membered ring lactams by cyclocarbonylation methodology," Journal of the American Chemical Society, vol. 118, no. 18, pp. 4264-4270, 1996.

[9] N. J. Farrell, "Transition metal complexes as drugs and chemotherapeutic agents," in Catalysis by Metal Complexes, B. R. James and R. Ugo, Eds., vol. 11, p. 46, Kluwer Academic Publishers, Dordrecht, The Netherlands, 1989.

[10] N. Manav, A. K. Mishra, and N. K. Kaushik, "Triphenyl phosphine adducts of platinum(IV) and palladium(II) dithiocarbamates complexes: a spectral and in vitro study," Spectrochimica Acta-Part A, vol. 60, no. 13, pp. 3087-3092, 2004.

[11] Y. E. Kwon, K. J. Whang, Y. J. Park, and K. H. Kim, "Synthesis, characterization and antitumor activity of novel octahedral Pt(IV) complexes," Bioorganic and Medicinal Chemistry, vol. 11, no. 8, pp. 1669-1676, 2003.

[12] C. Marzano, A. Trevisan, L. Giovagnini, and D. Fregona, "Synthesis of a new platinum(II) complex: anticancer activity and nephrotoxicity in vitro," Toxicology in Vitro, vol. 16, no. 4, pp. 413-419, 2002.

[13] K. Lemma, S. K. C. Elmroth, and L. I. Elding, "Substitution reactions of $[\mathrm{Pt}(\text { dien }) \mathrm{Cl}]^{+},[\mathrm{Pt}(\text { dien })(\mathrm{GSMe})]^{2+}$, cis- $\left[\mathrm{PtCl}_{2}\left(\mathrm{NH}_{3}\right)_{2}\right]$ and cis- $\left[\mathrm{Pt}\left(\mathrm{NH}_{3}\right)_{2}(\mathrm{GSMe})_{2}\right]^{2+}(\mathrm{GSMe}=\mathrm{S}$-methylglutathione $)$ with some sulfur-bonding chemoprotective agents," Journal of the Chemical Society, Dalton Transactions, no. 7, pp. 1281-1286, 2002.

[14] D. Fregona, L. Giovagnini, L. Ronconi et al., "Pt(II) and Pd(II) derivatives of ter-butylsarcosinedithiocarbamate: synthesis, chemical and biological characterization and in vitro nephrotoxicity," Journal of Inorganic Biochemistry, vol. 93, no. 3-4, pp. 181-189, 2003.

[15] R. Mital, N. Jain, and T. S. Srivastava, "Synthesis, characterization and cytotoxic studies of diamine and diimine palladium(II) complexes of diethyldithiocarbamate and binding of these and analogous platinum(II) complexes with DNA ", Inorganica Chimica Acta, vol. 166, no. 1, pp. 135-140, 1989.
[16] G. Faraglia, D. Fregona, S. Sitran et al., "Platinum(II) and palladium(II) complexes with dithiocarbamates and amines: synthesis, characterization and cell assay," Journal of Inorganic Biochemistry, vol. 83, no. 1, pp. 31-40, 2001.

[17] Y. Arikawaa and M. Onishi, "Reductive N-N coupling of NO molecules on transition metal complexes leading to $\mathrm{N}_{2} \mathrm{O}$," Coordination Chemistry Reviews, vol. 256, no. 5-8, pp. 468-478, 2012.

[18] P. I. O’Dwyer, J. Stevenson, and S. Johnson, “Clinical status of cisplatin, carboplatin and other platinum-based antitumor drugs," in Cisplatin: Chemistry and Biochemisry of a Leading Anticancer Drug, B. Lippert, Ed., pp. 31-69, Wiley-VCH, Weinheim, Germany, 1999.

[19] A. Scozzafava, A. Mastrolorenzo, and C. T. Supuran, "Arylsulfonyl-N,N-diethyl-dithiocarbamates: a novel class of antitumor agents," Bioorganic and Medicinal Chemistry Letters, vol. 10, no. 16, pp. 1887-1891, 2000.

[20] A. Divsalar, A. A. Saboury, R. Yousefi, A. A. MoosaviMovahedi, and H. Mansoori-Torshizi, "Spectroscopic and cytotoxic studies of the novel designed palladium(II) complexes: $\beta$ Lactoglobulin and K562 as the targets," International Journal of Biological Macromolecules, vol. 40, no. 4, pp. 381-386, 2007.

[21] G. Faraglia, L. Sindellari, and S. Sitran, "Thermal S-demethylation in palladium(II) and platinum(II) complexes with S-methyl N,N-dialkyldithiocarbamates," Thermochimica Acta, vol. 161, no. 1, pp. 63-73, 1990.

[22] A. I. Maztesanz, J. M. Perez, P. Navarro, J. M. Moreno, E. Colacio, and P. Souza, "Synthesis and characterization of novel palladium(II) complexes of bis(thiosemicarbazone). Structure, cytotoxic activity and DNA binding of Pd(II)-benzyl bis(thiosemicarbazonate)," Journal of Inorganic Biochemistry, vol. 76, no. 1, pp. 29-37, 1999.

[23] M. M. A. Mohammad and M. M. Shoukry, "Complex formation equilibria of palladium(II) complexes involving $N, N^{\prime}$ dimethylethylenediamine, DNA constituents and cyclobutane dicarboxylic acid. The catalysis of glycine methyl ester hydrolysis through complex formation," Polyhedron, vol. 21, no. 2, pp. 167-173, 2001.

[24] B. Taqui Khan, K. Najmuddin, S. Shamsuddin, K. Annapoorna, and J. Bhatt, "Synthesis, antimicrobial, and antitumor activity of a series of palladium(II) mixed ligand complexes," Journal of Inorganic Biochemistry, vol. 44, no. 1, pp. 55-63, 1991.

[25] R. V. Singh, N. Fahmi, and M. K. Biyala, "Coordination behavior and biopotency of $\mathrm{N}$ and $\mathrm{S} / \mathrm{O}$ donor ligands with their palladium(II) and platinum(II) complexes," Journal of the Iranian Chemical Society, vol. 2, no. 1, pp. 40-46, 2005.

[26] H. Mansoori-Torshizi, M. Islami-Moghaddam, and A. A. Saboury, "A microcalorimetry and spectroscopy study on the interaction of BSA with 2,2'-bipyridine octylglycinato palladium(II) nitrate," Acta Biochimica et Biophysica Sinica, vol. 35, no. 10 , pp. 886-890, 2003. 

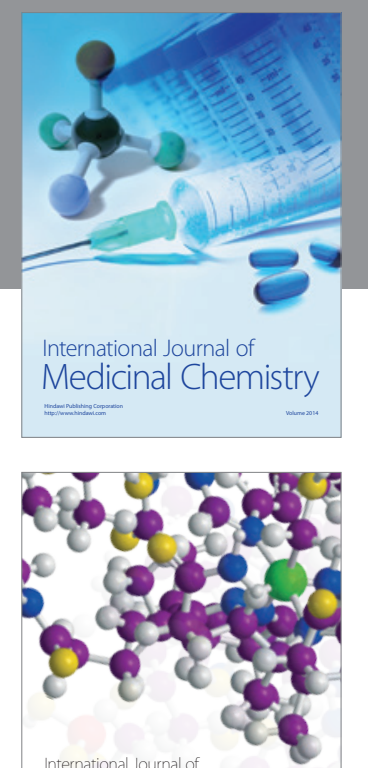

\section{Carbohydrate} Chemistry

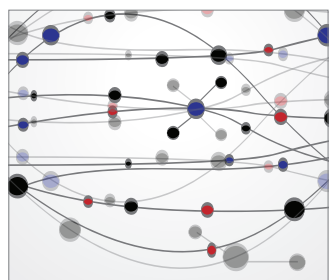

The Scientific World Journal
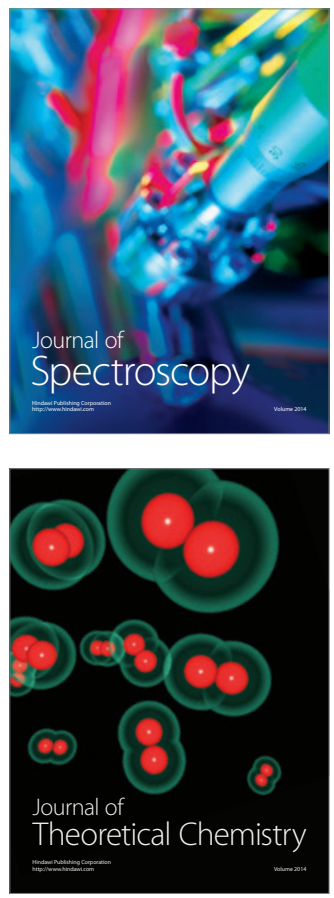
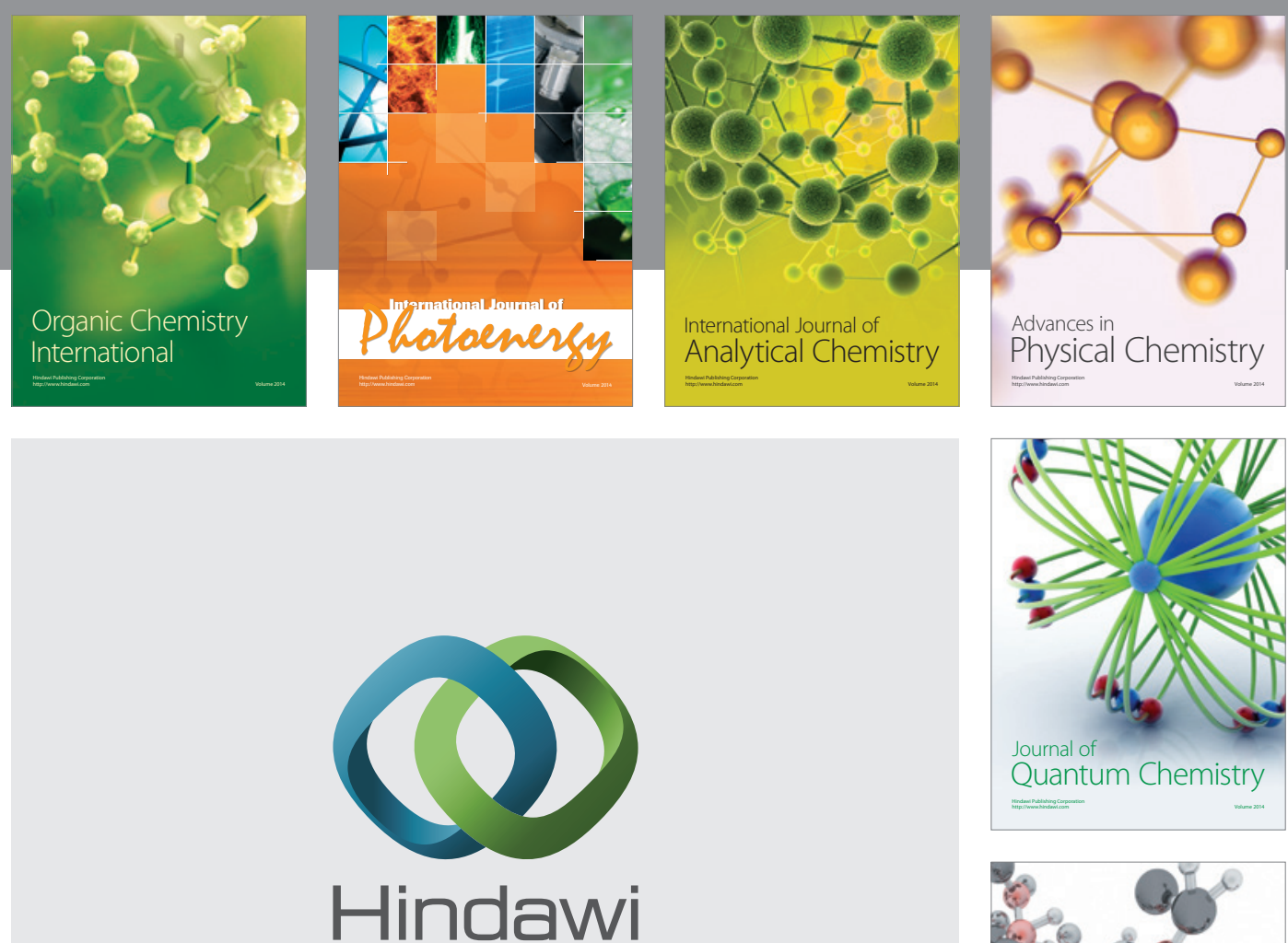

Submit your manuscripts at

http://www.hindawi.com

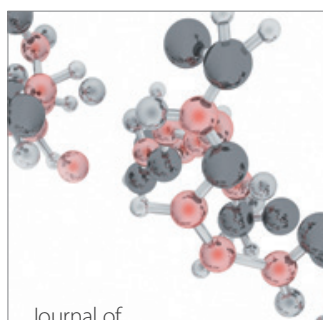

Analytical Methods

in Chemistry

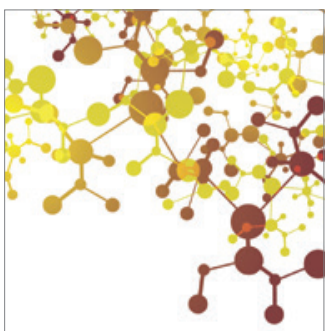

Journal of

Applied Chemistry

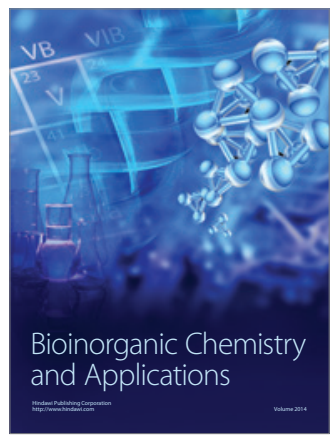

Inorganic Chemistry
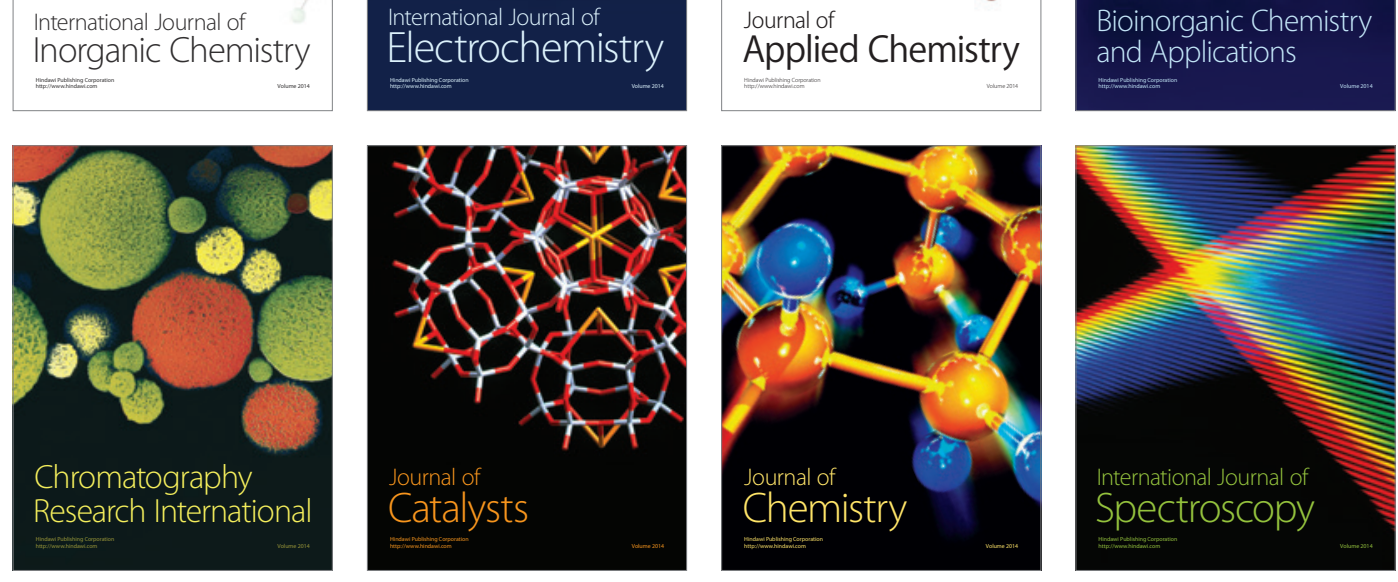